\title{
French norm industries/ knowledge review and regulative implementation prospectives
}

\author{
C. Cazala ${ }^{1}$, N. Pires ${ }^{1}$, G. Loriot $^{1}$, T. Doursout ${ }^{1}$, M.-L. Perrin ${ }^{2}$ and R. Rivas ${ }^{2}$ \\ 1 Institut de Radioprotection et de Sûreté Nucléaire (IRSN), BP. 17, \\ 92262 Fontenay-aux-Roses Cedex, France \\ 2 Autorité de Sûreté Nucléaire (ASN), 6 place du Colonel Bourgoin, 75012 Paris, France
}

\begin{abstract}
Over the last 5 years France gained a feedback on its NORM industries situation. Regulation imposes to the operators to assess effective doses for workers and members of the public. Theses data were used to update the list of industrial sectors to be regulated for NORM use or storage.
\end{abstract}

\section{INTRODUCTION}

According to the council Directive 96/29 Euratom [1], handling or storing NORM or TENORM materials has to be regarded from the radiological protection point of view. These requirements were implemented in French regulation. The main document is the Ministerial order of May 25, 2005 relative to activities operating NORM whose radioactive properties are not used [2]. French regulation imposes to operators to characterize raw materials, by products, products, waste and effluent. Their radioactive composition has to be investigated to assess effective doses for workers and the population induced by NORM industries.

Since 2005, more than 90 studies were addressed to the French Nuclear Safety Authority (ASN) and the Institute for Radiological protection and Nuclear Safety (IRSN) from nine of the ten NORM industrial sectors identified by the administration.

These studies constitute a valuable source of data to construct a general feedback on radioactive levels of materials and effective doses associated with NORM industries. To proceed, ASN asked IRSN to conduct a critical review of studies and to draw conclusions on theses issues. Simultaneously, on site administrative inspections were carried out by the ASN.

Overview and inspections conclusions were used to check the enforcement of regulation and to put forward an update of the national regulation, especially the revision of the list of industrial sectors concerned by NORM regulation.

\section{INVENTORY OF AVAILABLE DATA}

Table 1 introduces the ten industrial sectors identified by French administration as potentially concerned by NORM issues and the corresponding breakdown of received studies.

The first comment which can be made is the discrepancy between industrial sectors considered. That may result from discrepancy of each sector development -in other words, the number of on going factories- on the national territory. One of the main difficulties was to list theses factories to estimate the breakdown of answer by industrial sectors. Unfortunately, this information is not available and the established list is non exhaustive.

Most of studies deal with occupational exposure and about $90 \%$ of them present a dose assessment for worker. Exposure to the member of the public is less considered. Even when it is, effective dose assessments are scare or rough. 
Table 1. Breakdown of studies from the different industrial sectors.

\begin{tabular}{lc}
\hline Industrial activities sets by the French ministerial order of May 25, 2005 & Part (\%) \\
\hline Production of refractory ceramics and smelting, metallurgy and glass industry & $49 \%$ \\
$\quad$ using them & $16 \%$ \\
Coal combustion in power plants & $15 \%$ \\
Production of zircon and baddeleyite, and smelting or metallurgy plants using it & $7 \%$ \\
Treatment of tin, aluminium, copper, titanium, niobium, bismuth and thorium ores & $6 \%$ \\
Production of phosphated fertilizers and phosphoric acid & $3 \%$ \\
Production or use of compounds with thorium & $2 \%$ \\
Treatment of lanthanides series and production of pigments containing them & $1 \%$ \\
Spas & $1 \%$ \\
Underground water treatment by filtration & $0 \%$ \\
Treatment of titanium dioxide &
\end{tabular}

\section{ACTIVITY LEVELS IN NORMS}

Most of measurements were conducted by gamma spectrometry. Uranium and thorium series have been divided into groups of radionuclides as recommended by the European Commission [3]. For each chain segment, an activity was determined as follow. When no more than one result is available for a group, it stands for the group. When several radionuclide activities were measured and their measurements are consistent, the average of more reliable activities stands for the group. For example, regarding the chain segment of ${ }^{226} \mathrm{Ra}^{+1}$, deconvolution of the ${ }^{226} \mathrm{Ra}$ gamma ray $(186.2 \mathrm{keV})$ and the ${ }^{235} \mathrm{U}$ gamma ray (185.7 keV) cannot be done accurately by the classic HP-Ge detectors (detectors made of High Purity Germanium) mainly used in studies, whereas the activity of ${ }^{214} \mathrm{~Pb}$ or ${ }^{214} \mathrm{Bi}$ is easy to measure with those detectors. So the average of activities of ${ }^{214} \mathrm{~Pb}$ and ${ }^{214} \mathrm{Bi}$ stands for the group of ${ }^{226} \mathrm{Ra}^{+}$.

Data were distributed among material categories and industrial sectors. Categories considered are raw materials, products and waste. The category "Products" includes final products and by-products and the category "Waste" includes solid waste, effluents, sludge and dust. $26 \%$ of materials considered by operators are raw materials, $34 \%$ are products and 39\% are waste. Industrial sectors considered are not exactly coherent with those identified in the Ministerial order of May, 25, 2005 (table 1): a sorting based on materials was chosen. Were considered: coal combustion, glass industry, production and use of zircon and baddeleyite, production of phosphated fertilizers, production of refractory ceramics, production or use of compounds with thorium, spas, treatment of aluminium ores, treatment of kaolin ores, treatment of lanthanides series, treatment of titanium ores and filtration of underground water.

The minimum/maximum/median values along with the first and the third quartile values have been determined for each group of material/industrial sector. Examples for ${ }^{226} \mathrm{Ra}$ and ${ }^{228} \mathrm{Ra}$ are given in figure 1 .

Conclusions of the data analysis are as follow:

- activity concentrations are highly dependent of material category and industrial sector;

- the highest activity concentrations are generally encontered in waste. This result highlight the "E" of TENORM;

- IAEA recommends an exemption level for NORM materials of $1000 \mathrm{~Bq} \cdot \mathrm{kg}^{-1}$. Activities are often higher than this limit. 55\% of the times for waste, $29 \%$ for products and $16 \%$ for raw materials.

- the number of radionuclides measured and the accuracy of their activity determination are barely enough to assess the secular equilibrium or radioactive disequilibrium that occurs in NORM.

\footnotetext{
${ }^{1}$ Symbol '+' after a nuclide denotes a segment chain headed by that nuclide, e.g. ${ }^{226} \mathrm{Ra}^{+}$corresponds to this segment chain: ${ }^{226} \mathrm{Ra},{ }^{222} \mathrm{Rn},{ }^{218} \mathrm{Po},{ }^{218} \mathrm{At},{ }^{214} \mathrm{~Pb},{ }^{214} \mathrm{Bi}$ and ${ }^{214} \mathrm{Po}$.
} 

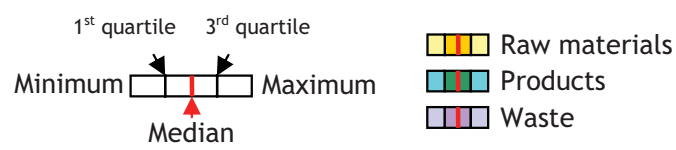

- IAEA's exemption level

(x) The number in brackets is the number of sample with an activity above LD

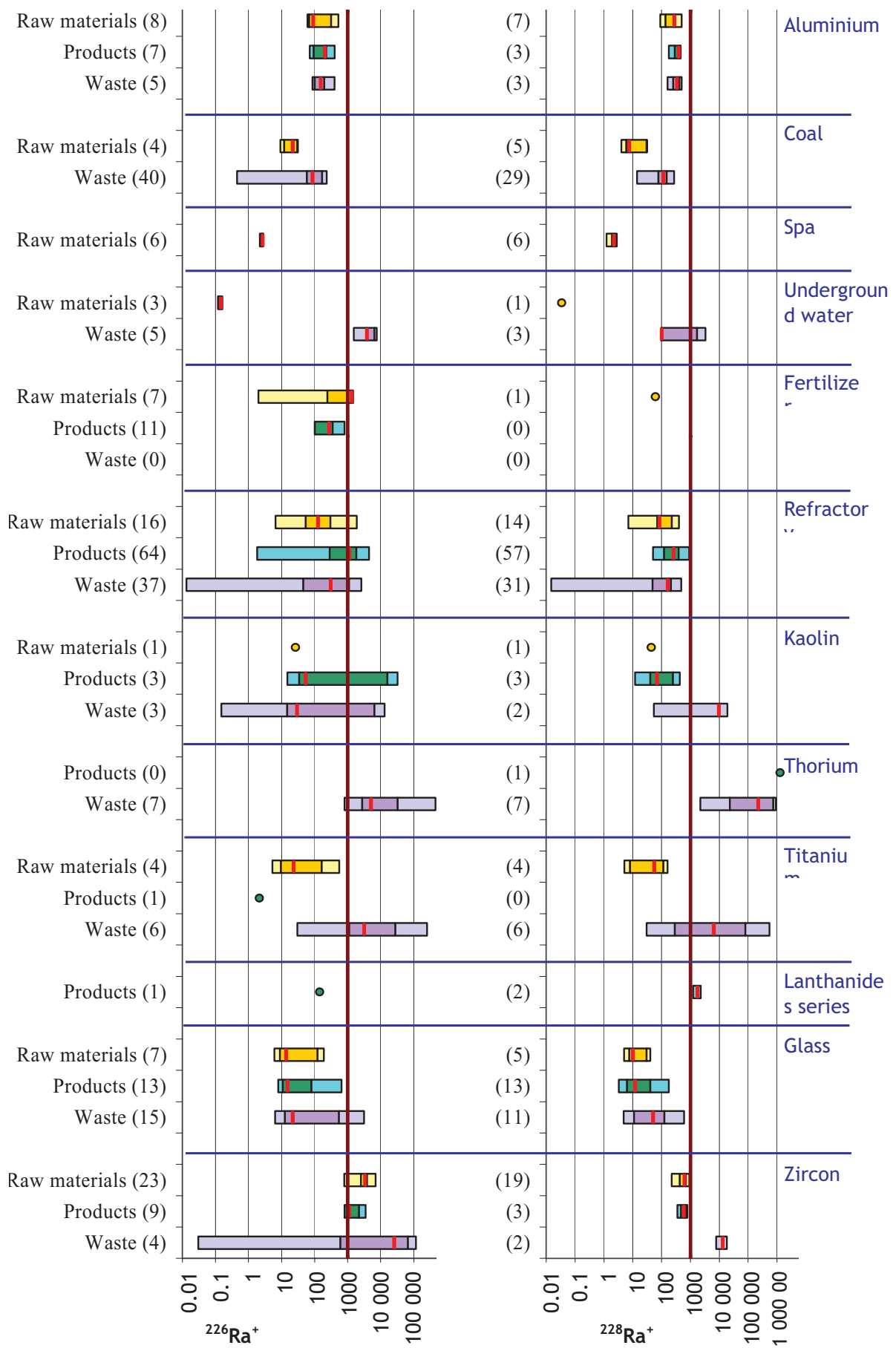

Figure 1. ${ }^{226} \mathrm{Ra}^{+}$and ${ }^{228} \mathrm{Ra}^{+}$activities $(\mathrm{Bq} / \mathrm{kg})$. 


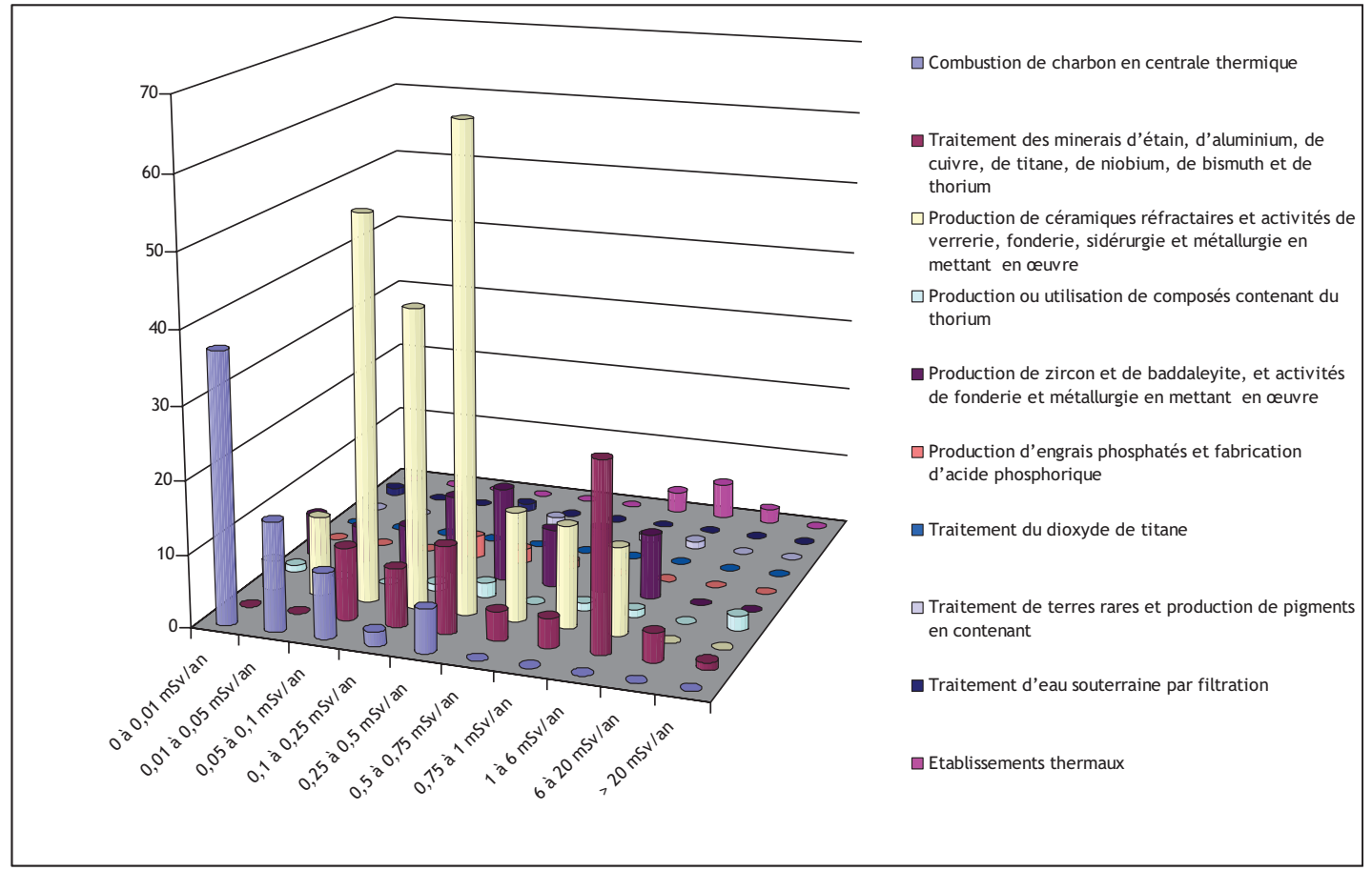

Figure 2. Effective doses assessed for workplaces.

- inbalances have been identified: activity of ${ }^{226} \mathrm{Ra}^{+}$group in waste (e.g. the category "underground water") or activity of ${ }^{210} \mathrm{~Pb}^{+}$group in ashes and dust related to heating processes is greater than the activites of the other groups of ${ }^{238} \mathrm{U}$ series.

\section{EXPOSURE LEVELS}

Internal exposure by inhalation of dust, radon and progenies has to be considered in effective dose assessment. More than 400 workplaces were investigated by operators, whereas no more than 45 cases of member of the public exposure were investigated.

Considering workplaces (figure 2), a third of doses are lower than $0.1 \mathrm{mSv} \cdot \mathrm{yr}^{-1}, 50 \%$ of doses are lower than $0.25 \mathrm{mSv} \cdot \mathrm{yr}^{-1}$ and $15 \%$ of doses are still greater than the effective dose limit of $1 \mathrm{mSv} \cdot \mathrm{yr}^{-1}$ established in France [4] for the public including workers from the non nuclear field. These results require further examination but, for some industrial activities, data show that occupational exposure is not a significant issue (see Pires et al., Third European IRPA Congress 2010 June 14-18, Helsinki, Finland). For example, in coal combustion power plants, more than 30 workplaces have been well assessed and no dose is greater than $1 \mathrm{mSv} \mathrm{yr}^{-1}$ which is still consistent with literature.

Main conclusions on dose assessment conducted by operators are: i) sometimes, internal or external exposure is not considered even it is a significant exposure pathway, ii) exposure due to inhalation of radon progenies is often not taken into account.

Considering exposure of the public (figure 3), 53\% of calculated effective doses are lower than 0.1 $\mathrm{mSv} . \mathrm{yr}^{-1}, 84 \%$ of doses are lower than $0.25 \mathrm{mSv} \cdot \mathrm{yr}^{-1}$ and $2 \%$ of doses are higher than the value of 1 $\mathrm{mSv} . \mathrm{yr}^{-1}$. This value is the limit for exposure of the public imposed by the national regulation.

Exposure of workers is more often and meticulously considered than exposure of the public. The main consequence is a better feedback for workers than for the members of the public. Often, dose 


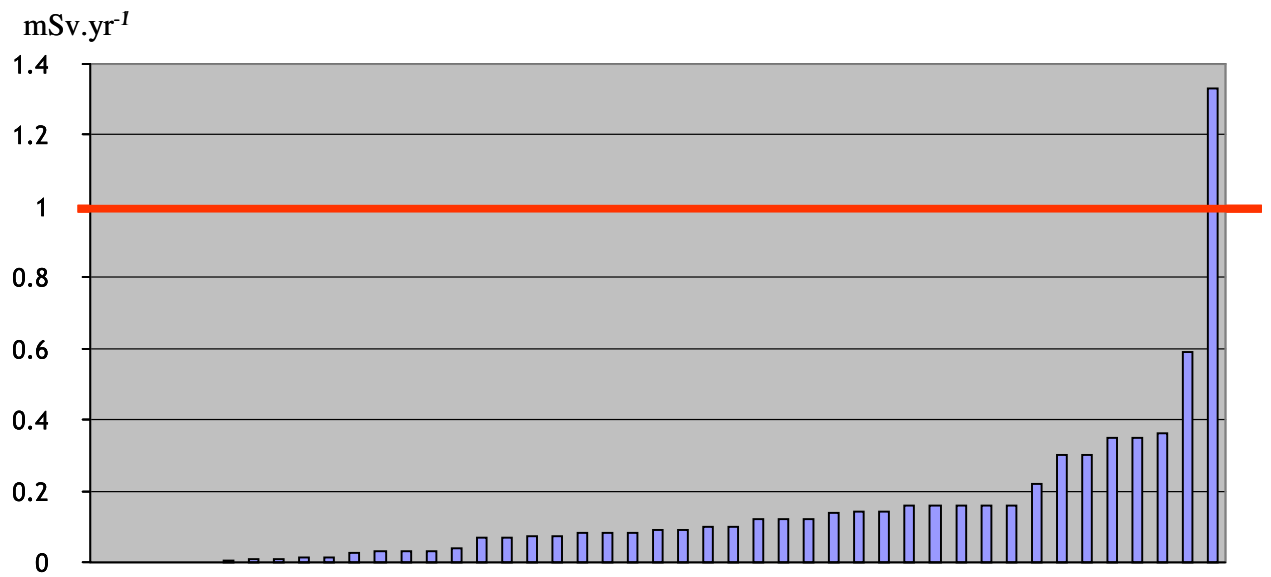

Figure 3. Effective doses calculated for the members of the public.

assessments for the public are based on very pessimistic assumptions - most of the times an unrealistic duration of exposure. This is for example the case for the value higher than $1 \mathrm{mSv}_{\mathrm{yr}} \mathrm{y}^{-1}$.

\section{CONCLUSION}

Based on feedback gained by IRSN and the French authorities from the studies conducted by operators, national regulation will be updated. Several issues will be considered.

Analysis of the activity level of material leads to focus on waste management. On the base of this analysis along with other sources of information, ASN drafted reports drawing solutions to improve NORM waste management. Main conclusions are:

- the difficulty to establish an exhaustive inventory of NORM waste,

- the necessity to improve the traceability of NORM waste

- the necessity to develop a NORM waste recording process.

Reuse of NORM waste and associated exposure for worker and member of the public is also considered as improvable in this document.

The review of studies feeds the revision process of the list of industrial sectors concerned by NORM. Industrial activities may be removed from the list, added to the list; several industrial sectors may be merged. They will be removed when occupational and public exposure is not a significant issue. They will be added when the management of waste presents difficulty due to their radiological content (detection of radioactivity at the entrance of landfill). Finally industrial sectors will be merged when materials are similar.

Up to now, regulation has not been updated but it is proposed to reduce the list from ten to eight industrial sectors. The revised list could be:

- Sn, $\mathrm{Cu}, \mathrm{Ti}, \mathrm{Ni}, \mathrm{Bi}$ and Th ore processing,

- production and use of material containing Th,

- production and use of $\mathrm{Zr}$ and Baddeleyite or material containing $\mathrm{Zr}$ or Baddeleyite,

- production of phosphoric acid,

- rare earth element processing, and production of pigment containing rare earth element,

- production of drinking or mineral water by filtration from underground resources,

- spas,

- papermaking. 
Extraction of petroleum and gas, geothermic installation may also be considered as NORM industries. The French regulation framework does not allow adding them to the list.

Within the framework of the Euratom 96/29 directive revision, exemption level of $1 \mathrm{~Bq} . \mathrm{g}^{-1}$ for NORM material is proposed. The French approach is base on dose assessment. Consequences of introduction of the exemption level in national regulation are still under consideration.

\section{References}

[1] Council Directive 96/29/Euratom of May 13, 1996 laying down basic safety standards for the protection of the health of workers and the general public against the dangers arising from ionizing radiation.

[2] Ministerial order of May 25, 2005 related to activities operating NORM not used because of their radioactive properties.

[3] Chen Q., Degrange J.-P., Gerchikov M. Y., Hillis Z. K., Lepicard S., Meijne E. I. M., Smith K. R., Van Weers A., Effluent and dose control from European Union NORM industries: Assessment of current situation and proposal for a harmonised Community approach - Volume 1: Main Report, Radiation Protection $\mathrm{n}^{\circ} 135$, Office for Official Publications of the European Communities, Luxembourg (2003).

[4] Code of public health, Article R.1333-8. 